\title{
Profitability of Polana raspberries production
}

\section{Opłacalność produkcji maliny odmiany Polana}

\author{
Alicja Baranowska ${ }^{1}$, Krystyna Zarzecka
}

\section{Summary}

Field experiments were conducted on commercial plantation with an area of 1.2 hectares between the years 2010-2011. The production was established on sandy soil. The research material consisted of data regarding an autumn variety of raspberries Polana. The aim of the study was to determine the profitability of Polana production on the basis of SGM (Standard Gross Margin). The obtained gross margin indicated that the production of raspberries was profitable. In the direct cost structure, the purchase of raspberry seedlings was one of the lowest expenses unlikely to some specific costs which covered labor hired to manual harvesting. Moreover, plant protection products as well as mineral fertilization shared significant fraction in cost structure, however, the value of the harvested crops exceeded the costs.

Key words: profitability of production, gross margin, raspberry yield, agrophages

\section{Streszczenie}

Badania polowe prowadzono w latach 2010-2011 na plantacji produkcyjnej o powierzchni 1,2 ha założonej na glebie lekkiej. Materiał badawczy stanowiły dane dotyczące produkcji jesiennej odmiany maliny Polana. Celem badań było określenie opłacalności produkcji maliny na podstawie nadwyżki bezpośredniej (SGM - Standard Gross Margin). Uzyskana nadwyżka bezpośrednia wykazała, że produkcja maliny była opłacalna. W strukturze kosztów bezpośrednich najtańszy był zakup sadzonek malin, a najdroższe koszty specjalistyczne, które obejmowały najem siły roboczej do ręcznego zbioru owoców malin. W strukturze kosztów bezpośrednich duży udział miały również środki ochrony roślin i nawożenie mineralne, jednak wartość zebranego plonu przewyższała poniesione koszty.

Słowa kluczowe: opłacalność produkcji, nadwyżka bezpośrednia, plon malin, agrofagi

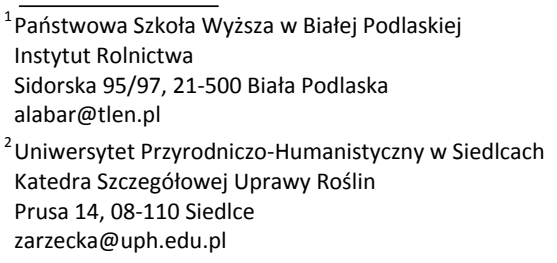




\section{Wstęp / Introduction}

Owoce jagodowe odgrywają ważną rolę w polskim sadownictwie $\mathrm{z}$ uwagi na znaczny udział $\mathrm{w}$ eksporcie na rynki europejskie i światowe, zarówno w postaci świeżej, jak i po obróbce technologicznej (Winiarska 1992; Łozowicka i wsp. 2010).

Systematyczny wzrost produkcji owoców jagodowych w ostatnich latach był konsekwencją zwiększającej się powierzchni uprawy maliny. Według danych GUS w 2010 roku polska produkcja tych owoców wyniosła 92,9 tys. ton. $\mathrm{Na}$ przestrzeni ostatnich dziesięciu lat zbiory wzrastały w średnim tempie - około 10\% rocznie (Stępka 2012). W 2012 roku zbiory malin w Polsce kształtowały się na rekordowym poziomie 123 tys. ton, tj. o 4\% więcej od zbiorów z 2011 roku (Wstępny szacunek 2012).

Malina właściwa (Rubus idaeus L.) to krzew z rodziny różowatych (Rosaceae). Jest jednym z ważniejszych i najstarszych gatunków roślin sadowniczych występujących w klimacie umiarkowanym. Owoce maliny nadają się do bezpośredniego spożycia i na mrożonki, są też bardzo dobrym surowcem dla przemysłu przetwórczego (Winiarska i wsp. 2005; Baranowska i Zarzecka 2012). Oprócz wartości odżywczych i smakowych mają również znaczenie dietetyczne i lecznicze. Są bogate w związki zapobiegające chorobom nowotworowym. Zawierają duże ilości cukrów prostych, barwników, kwasów organicznych, pektyn, związków śluzowych. Stanowią cenne źródło naturalnych antyoksydantów, a zwłaszcza witamin: $\mathrm{C}, \mathrm{E}$ oraz witamin $\mathrm{z}$ grupy $\mathrm{B}: \mathrm{B}_{1}, \mathrm{~B}_{2}, \mathrm{~B}_{6}$, a także związków mineralnych: soli potasu, magnezu, wapnia, żelaza (Krauze-Baranowska i Majdan 2009).

W ostatnich latach w Polsce nastąpił znaczny rozwój produkcji jesiennych odmian maliny, powtarzających owocowanie, które cieszą się dużym zainteresowaniem producentów, a zbierane są od sierpnia aż do pierwszych przymrozków. Do produkcji maliny zachęca duże zapotrzebowanie na owoce deserowe i przeznaczone do przetwórstwa, niezawodność uprawy, a także szybkie wejście krzewów w okres owocowania (Danek 2009). Produkcja owoców jagodowych obarczona jest jednak dużym ryzykiem wynikającym w znacznym stopniu ze zmienności cen zbytu owoców i wzrostu cen środków produkcji. Podstawowym czynnikiem decydującym o opłacalności produkcji jest: wielkość plonów, cena zbytu i ponoszone koszty, wśród których duży udział ma siła robocza (Kowalczyk 2006; Paszko 2006). O opłacalności produkcji owoców jagodowych decydują również koszty ochrony plantacji przed agrofagami (choroby, szkodniki, chwasty) (Łabanowska 2000; 2008; Vetek i wsp. 2006; Brzozowski i Klimek 2010).

Celem badań było określenie opłacalności produkcji maliny jesiennej odmiany Polana, którą uprawiano na glebie lekkiej.

\section{Materiały i metody / Materials and methods}

Badania przeprowadzono w latach 2010-2011 na plantacji produkcyjnej, o powierzchni 1,2 ha. Przedmiotem badań były owoce maliny jesiennej, powtarzającej owoco- wanie, odmiany Polana. Nasadzenia zostały wykonane w rozstawie rzędów $3,0 \mathrm{~m} \times 0,5 \mathrm{~m}$. Plantację założono w 2009 roku na glebie wytworzonej z piasków gliniastych ( $\mathrm{pH}$ w $\mathrm{KCl}=4,9$ ) kompleksu żytniego dobrego, klasy IVb, o niskiej zasobności w przyswajalny potas i magnez, średniej zasobności w przyswajalny fosfor. Jesienią stosowano nawożenie mineralne: fosforowe $\mathrm{P}-32,86$ $\left(100 \mathrm{P}_{2} 0_{5} \times 0,44\right) \mathrm{kg} / \mathrm{ha}$ (superfosfat potrójny $\left.46 \%\right)$ i K $112,10\left(150 \mathrm{~K}_{2} 0 \times 0,83\right) \mathrm{kg} / \mathrm{ha}$ (sól potasowa $60 \%$ ). Wiosną wysiewano nawozy azotowe (saletra amonowa 34\%) w dawce N $100 \mathrm{~kg} / \mathrm{ha}$ oraz nawozy wapniowomagnezowe (WapMag $\mathrm{CaO} 30 \%, \mathrm{MgO} 15 \%$ ) w dawce $480 \mathrm{~kg} /$ ha i nawóz wieloskładnikowy z mikroelementami Yara Mila Complex 12-11-18 (N - 12\%, P - 11\%, K $18 \%, \mathrm{Mg}-2,7 \%, \mathrm{~S}-8 \%+$ mikroelementy) w dawce $300 \mathrm{~kg} / \mathrm{ha}$. Przed chorobami grzybowymi (szarą pleśnią i zamieraniem pędów malin) plantację chroniono preparatem Rovral Aquaflo $500 \mathrm{SC}$ w dawce 1,5 1/ha, następnie stosowano dwukrotne opryskiwanie fungicydem Teldor 500 SC w dawce 1,5 1/ha. Przeciw szkodnikom malin (pędrakom, drutowcom) stosowano preparat Dursban $480 \mathrm{EC} w$ dawce 3,0 1/ha. Do ochrony plantacji przed kwieciakiem malinowcem i pryszczarkiem namalinkiem łodygowym stosowano insektycyd Fastac $100 \mathrm{EC}$ w dawce 0,18 1/ha. Chwasty zwalczano herbicydami: Lontrel $300 \mathrm{SL} w$ ilości 0,4 1/ha i Kerb $500 \mathrm{SC}-2,0$ 1/ha. Maliny zbierano ręcznie $\mathrm{w}$ terminie od pierwszej dekady sierpnia do drugiej dekady października w fazie pełnej dojrzałości technologicznej owoców. Średni plon owoców malin z 1 hektara wynosił $6080 \mathrm{~kg} / \mathrm{ha}$. W kosztach bezpośrednich uwzględniono koszty materiałowe (sadzonki, nawozy mineralne, środki ochrony roślin) oraz koszty specjalistyczne (zbiór ręczny malin, zabiegi chemiczne). Średnie ceny materiałów i plonu przyjęto według cen zakupu i sprzedaży z 2010 i 2011 roku. Wartość plonu maliny obliczono na podstawie iloczynu zebranego plonu i cen sprzedaży owoców. Koszty bezpośrednie stanowiła: suma kosztów sadzonek malin, środków ochrony roślin, nawozów mineralnych, innych kosztów bezpośrednich oraz kosztów specjalistycznych. Opłacalność produkcji 1 ha maliny określono kategorią nadwyżki bezpośredniej stanowiącej różnicę pomiędzy wartością rynkową plonu i kosztami bezpośrednimi obejmującymi zużycie materiałów oraz koszty specjalistyczne (Augustyńska-Grzymek i wsp. 2009).

\section{Wyniki i dyskusja / Results and discussion}

Malina właściwa to jedna $\mathrm{z}$ ważniejszych roślin sadowniczych w Polsce. Produkcja owoców maliny od wielu lat ma tendencje wzrostowe. Udział zbiorów malin w ogólnych zbiorach owoców jagodowych w kraju, w latach 2007-2012 zwiększył się z 13 do 23\%. Coraz większe znaczenie $\mathrm{w}$ rozwoju tej produkcji maja odmiany jesienne, powtarzające owocowanie, zbierane od sierpnia aż do pierwszych przymrozków. Nie wymagają one tak intensywnej ochrony przed agrofagami, jak odmiany owocujące latem, nadają się do zbioru mechanicznego, owoce są cenione $\mathrm{w}$ przemyśle przetwórczym, zwłaszcza w zamrażalnictwie. Ich skup jest bardziej wydłużony w czasie i nie 
Tabela 1. Koszty bezpośrednie produkcji 1 ha maliny (średnia z lat 2010-2011)

Table 1. Total direct costs of production per hectare of raspberries (average for 2010-2011)

\begin{tabular}{|c|c|c|c|c|c|}
\hline $\begin{array}{l}\text { Wyszczególnienie } \\
\text { Specification }\end{array}$ & $\begin{array}{l}\text { Jednostki } \\
\text { miary } \\
\text { Units }\end{array}$ & $\begin{array}{c}\text { Ilość } \\
\text { Number }\end{array}$ & $\begin{array}{c}\text { Cena } \\
\text { jednostkowa } \\
\text { Price per unit } \\
{[\text { PLN }]}\end{array}$ & $\begin{array}{c}\text { Wartość } \\
\text { Value } \\
\text { [PLN] }\end{array}$ & $\begin{array}{c}\text { Struktura } \\
\text { kosztów } \\
\text { The } \\
\text { structure cost } \\
{[\%]}\end{array}$ \\
\hline \multicolumn{6}{|l|}{ Koszty bezpośrednie - Direct costs: } \\
\hline Sadzonki z zakupu - Purchased seedlings 20\% & szt./ha & 1200 & 1,00 & 1200 & 7,40 \\
\hline \multicolumn{4}{|c|}{ Razem środki ochrony roślin, w tym - Total pesticides, of which: } & 2701 & 16,65 \\
\hline - fungicydy - fungicides & \multirow{3}{*}{ 1/ha } & 4,5 & 398,0 & 1791 & 11,04 \\
\hline - insektycydy - insecticides & & 3,18 & 69,0 & 219 & 1,35 \\
\hline - herbicydy - herbicides & & 2,4 & 288,0 & 691 & 4,26 \\
\hline \multicolumn{4}{|l|}{ Razem nawozy mineralne - Total fertilizers, of which: } & 1924 & 11,85 \\
\hline - wapniowo-magnezowe - calcium and magnesium & \multirow{5}{*}{$\mathrm{kg} / \mathrm{ha}$} & 480 & 59,0 & 283 & 1,74 \\
\hline - wieloskładnikowe - multicomponent & & 300 & 300,0 & 900 & 5,55 \\
\hline - azotowe - nitrogen & & 100 & 150,0 & 150 & 0,92 \\
\hline - fosforowe - phosphorus & & 100 & 292,0 & 292 & 1,80 \\
\hline - potasowe - potassium & & 150 & 199,0 & 299 & 1,84 \\
\hline Inne koszty bezpośrednie - Other direct costs & \multirow[b]{2}{*}{$\mathrm{PLN} / \mathrm{ha}$} & & & 5825 & 35,90 \\
\hline Koszty specjalistyczne - Crop specific costs & & & & 10400 & 64,10 \\
\hline $\begin{array}{l}\text { Ogółem koszty bezpośrednie na } 1 \text { ha } \\
\text { Total direct costs per } 1 \text { ha }\end{array}$ & & & & 16225 & 100 \\
\hline
\end{tabular}

Źródło: opracowanie własne - Source: own calculations

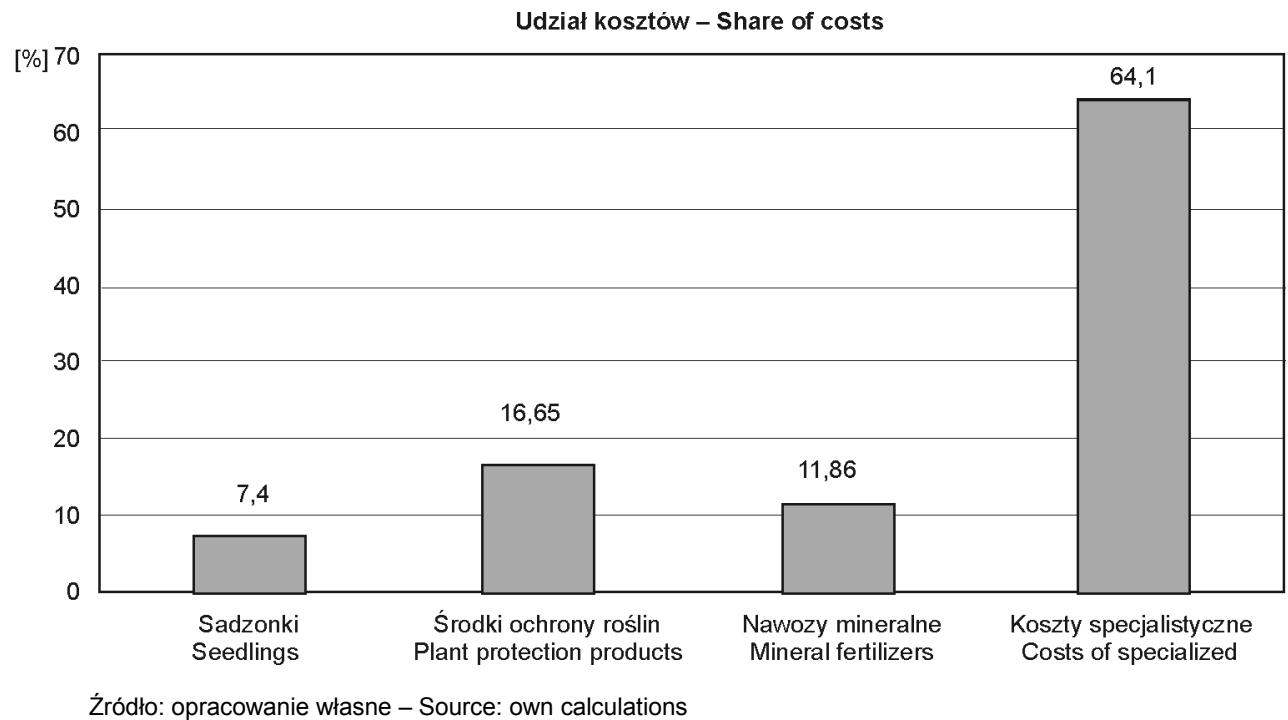

Rys. 1. Struktura kosztów produkcji maliny odmiany Polana (średnia z lat 2010-2011)

Fig. 1. The structure of production costs of Polana raspberry (average for 2010-2011)

zbiega się z podażą innych owoców jagodowych (Winiarska i wsp. 2005; Stępka 2012). W pracy przedstawiono opłacalność produkcji jednego hektara maliny, uwzględniając: koszty bezpośrednie, wartość plonu malin oraz nadwyżkę bezpośrednią (tab. 1,2).

Wśród kosztów bezpośrednich najtańszy był zakup sadzonek maliny i wynosił on 1200,0 PLN/ha, co stanowiło 7,40\% w strukturze kosztów (tab. 1). Największe były natomiast koszty specjalistyczne, które obejmowały głównie najem siły roboczej do zbioru ręcznego malin oraz koszty zabiegów chemicznych i wynosiły one średnio $10400 \mathrm{PLN} / \mathrm{ha}$. W przeliczeniu procentowym stanowiły one $64,10 \% \mathrm{w}$ strukturze kosztów uprawy malin (tab. 1, rys. 1). Również zdaniem Kowalczyka (2006) w gospodarstwach sadowniczych nakłady robocizny na 1 ha były trzykrotnie większe, niż w gospodarstwach prowadzących typową produkcję rolniczą. Wśród upraw sadowniczych największą pracochłonnością charakteryzowała się uprawa 
maliny, a wskaźnik mechanizacji prac nie przekraczał $10 \%$. Również zdaniem innych autorów specyfika produkcji owoców jagodowych obok znacznych kosztów i względnie wysokiej dochodowości odznaczała się dużą pracochłonnością. W całym procesie wytwarzania szczególną rolę w kształtowaniu poziomu kosztów odgrywały nakłady pracy na zbiór ręczny owoców (Paszko 2006, 2008; Rabcewicz i Wawrzyńczak 2006; Brzozowski i Klimek 2010). Zdaniem Kowalczyka i wsp. (2008) zbiór owoców maliny kombajnem jest obecnie jednym z podstawowych sposobów umożliwiających zwiększenie areału uprawy oraz wzrostu opłacalności produkcji.

Tabela 2. Opłacalność produkcji 1 ha maliny (średnia z lat 20102011)

Table 2. Profitability of production per hectare of raspberries (average for 2010-2011)

\begin{tabular}{l|c}
\hline \multicolumn{1}{c|}{$\begin{array}{c}\text { Wyszczególnienie } \\
\text { Specification }\end{array}$} & $\begin{array}{c}\text { Wartość } \\
\text { Value } \\
{[\text { PLN] }}\end{array}$ \\
\hline $\begin{array}{l}\text { Wartość plonu malin } \\
\text { Value of raspberry yield }\end{array}$ & 18848 \\
\hline $\begin{array}{l}\text { Ogółem koszty bezpośrednie na 1 ha } \\
\text { Total direct costs per 1 ha }\end{array}$ & 16225 \\
\hline $\begin{array}{l}\text { Nadwyżka bezpośrednia } \\
\text { Gross margin }\end{array}$ & 2623 \\
\hline
\end{tabular}

Źródło: opracowanie własne - Source: own calculations

Koszt zakupu środków ochrony roślin wynosił średnio 2701,0 PLN/ha i stanowił 16,65\% w strukturze kosztów bezpośrednich (tab. 1, rys. 1). Wśród środków ochrony roślin najdroższe były fungicydy, stanowiły one 11,04\% w strukturze kosztów bezpośrednich, następnie herbicydy - 4,26\%, a najtańsze były insektycydy i stanowiły one
1,35\%. Zdaniem Brzozowskiego (2003) koszty te można obniżyć poprzez ograniczenie liczby zabiegów ochrony oraz dokonywanie częstszych lustracji plantacji i ocen zagrożenia agrofagami.

Nawozy mineralne stanowiły średnio $11,85 \%$ w strukturze kosztów. Najdroższe było nawożenie nawozem mineralnym, wieloskładnikowym Yara Mila Complex 12-11-18 $(\mathrm{N}-12 \%, \mathrm{P}-11 \%, \mathrm{~K}-18 \%, \mathrm{Mg}-2,7 \%, \mathrm{~S}-8 \%+$ mikroelementy) i stanowiło ono 5,55\% w strukturze kosztów bezpośrednich (tab. 1, rys. 1). Na pozytywny wpływ nawozów mineralnych, wieloskładnikowych na plon malin zwracają również uwagę Krawiec i Rybczyński (2010).

Średnia wartość plonu malin z lat 2010-2011 wynosiła 18 848,0 PLN/ha, a nadwyżki bezpośredniej 2623,0 PLN/ha (bez dopłat bezpośrednich do produkcji owoców miękkich) (tab. 2). Z powyższych obliczeń wynika, że produkcja maliny jest opłacalna nawet przy średnim plonie, jaki zebrano z plantacji.

\section{Wnioski / Conclusions}

1. W strukturze kosztów bezpośrednich uprawy maliny powtarzającej owocowanie największe były koszty specjalistyczne, które obejmowały głównie najem siły roboczej oraz koszty zbiegów chemicznych.

2. Środki ochrony roślin stanowiły średnio 16,65\% w strukturze kosztów bezpośrednich, a najdroższe były fungicydy.

3. Nawożenie mineralne stanowiło średnio $11,85 \%$ kosztów bezpośrednich, najdroższe było nawożenie plantacji maliny nawozem wieloskładnikowym.

4. Produkcja maliny powtarzającej owocowanie odmiany Polana w latach 2010-2011 była opłacalna.

\section{Literatura / References}

Augustyńska-Grzymek I., Cholewa M., Dziewulski M., Orłowski A., Skarżyńska A., Ziętek I., Zmarzłowski K. 2009. Produkcja, koszty i nadwyżka bezpośrednia wybranych produktów rolniczych w 2008 roku. Raport Programu Wieloletniego 140. IERiGŻ - PIB, Warszawa, 163 ss.

Baranowska A., Zarzecka K. 2012. Opłacalność uprawy malin. Rocz. Nauk. Stowarzyszenia Ekonomistów Rolnictwa i Agrobiznesu 14 (1): 26-28.

Brzozowski P. 2003. Koszty opłacalności produkcji porzeczek i agrestu. s. 82-87. Ogólnopol. Konf. Porzeczkowa i Agrestowa. Inst. Sad. i Kwiac., Skierniewice, 24 kwietnia 2003, 93 ss.

Brzozowski P., Klimek G. 2010. Opłacalność produkcji wiśni w Polsce w latach 2000-2010. Zesz. Nauk. Inst. Sad. i Kwiac. 18: $181-193$

Danek J. 2005. 25 lat hodowli maliny i jeżyny w Sadowniczym Zakładzie Doświadczalnym ISK w Brzeżnej. s. 165-166. Materiały X Ogólnopol. Nauk. Zjazdu Hodowców Roślin Ogrodniczych. Zmienność genetyczna - utrzymanie, tworzenie i wykorzystanie w hodowli roślin. Inst. Sad. i Kwiac., Skierniewice, 15-16 lutego 2005, 192 ss.

Danek J. 2009. Uprawa maliny i jeżyny. Hortpress, Warszawa, 74 ss.

Kowalczyk Z. 2006. Poziom i struktura nakładów pracy w wybranych gospodarstwach sadowniczych. Inż. Roln. 11 (86): $209-214$.

Kowalczyk J., Zarajczyk J., Leszczyński N. 2008. Analiza jakości zbioru malin kombajnem „Natalia” firmy Weremczuk. Inż. Rol. 2 (100): 89-94.

Krauze-Baranowska M., Majdan M. 2009. Owoce malin - źródło cennych leczniczo metabolitów wtórnych i witamin. Panacea 1 (26): $14-15$.

Krawiec P., Rybczyński R. 2010. Efektywność fertygacji w malinach odmian powtarzających. Acta Agrophys. 16 (2): $347-358$.

Łabanowska B. 2000. Możliwości zwalczania kwieciaka malinowca (Anthonomus rubi Hbst.) i kistnika malinowca (Byturus tomentosus F.) w integrowanej produkcji owoców maliny. [Strawberry blossom weevil (Anthonomus rubi Hbst.) and raspberry beetle (Byturus 
tomentosus F.) and their control possibility in the integrated fruit production of raspberry]. Prog. Plant Prot./Post. Ochr. Roślin 40 (2): 506-509.

Łabanowska B. 2008. Efektywność insektycydów z grupy neonikotynoidów w zwalczaniu mszyc (Aphididae) i pryszczarków (Cecidomyidae) na porzeczce czarnej i malinie. Zesz. Nauk. Inst. Sad. i Kwiac. 16: 179-189.

Łozowicka B., Jankowska M., Rutkowska E., Kaczyński P. 2010. Pozostałości fungicydów i insektycydów w owocach jagodowych i sokach z owoców jagodowych. [Fungicide and insecticide residues in berry fruits and fruit juices]. Prog. Plant Prot./Post. Ochr. Roślin 50 (3): 1445-1451.

Paszko D. 2006. Wybrane problemy rachunku ekonomicznego na przykładzie specjalistycznych gospodarstw sadowniczych województwa lubelskiego. Zesz. Nauk. Inst. Sad. i Kwiac. 14: 96-106.

Paszko D. 2008. Wpływ zmienności kosztów siły roboczej na opłacalność produkcji owoców jagodowych. Zesz. Nauk. Inst. Sad. i Kwiac. 16: 223-234.

Rabcewicz J., Wawrzyńczak P. 2006. Możliwości zmechanizowania produkcji owoców z krzewów jagodowych. s. 81-92. Ogólnopol. Konf. Sadow. nt. Nowe odmiany i technologie uprawy krzewów jagodowych. Inst. Sadownictwa i Kwiaciarstwa, Skierniewice, 27 kwietnia 2006, 100 ss

Stępka G. 2012. Jak maliny to jesienne. www.ogrodinfo.pl/rosliny-jagodowe/, dostęp: 20.01.2013.

Winiarska J. 1992. Niektóre cechy biologiczne i produkcyjne owocujących pędów dziesięciu odmian maliny (Rubus idaeus L.). Praca hab., AR Lublin. Rozpr. Nauk. 148, 60 ss.

Winiarska J., Szember E., Żmuda E., Murawska D. 2005. Porównanie składu chemicznego owoców wybranych odmian maliny Rubus idaeus L. Ann. UMCS, Sec. E, 15: 29-33.

Wstępny szacunek głównych ziemiopłodów rolnych i ogrodniczych w 2012 roku. 2012. www.stat. gov.pl, dostęp: 24.01.2013.

Vetek G., Fail J., Penzes B. 2006. Susceptibility of raspberry cultivars to the raspberry cane midge (Resseliella theobaldi Barnes). J. Fruit Ornam. Plant Res. 14 (Suppl. 3): 61-66. 